\title{
An assessment of diet overlap of two mesocarnivores in the North West Province, South Africa
}

\author{
Ingrid van der Merwe', Craig J. Tambling ${ }^{2 *}$, Michelle Thorn ${ }^{2,3}$, \\ Dawn M. Scott', Richard W. Yarnell ${ }^{4}$, Matthew Green ${ }^{3}$, \\ Elissa Z. Cameron² \& Philip W. Bateman ${ }^{2}$ \\ ${ }^{1}$ Department of Zoology and Entomology, University of Pretoria, Pretoria, 0002 South Africa. \\ ${ }^{2}$ Mammal Research Institute, Department of Zoology and Entomology, University of Pretoria, \\ Pretoria, 0002 South Africa \\ ${ }^{3}$ University of Brighton, Biology Division, Cockcroft Building, Lewes Road, Moulsecoomb, \\ Brighton, BN2 4GJ, U.K. \\ ${ }^{4}$ School of Animal, Rural and Environment Sciences, Nottingham Trent University, Brackenhurst, \\ Southwell, Nottinghamshire, NG25 OQF, U.K. \\ Received 26 March 2009. Accepted 20 August 2009
}

We used scat analysis to study the diet of two sympatric medium-sized carnivores: brown hyaena and black-backed jackal, in the North West Province of South Africa. Seven major dietary categories were identified from the scats, with mammal remains being most common for both species. Brown hyaena scats contained more large mammal remains, which together with the presence of invertebrates (in $50 \%$ of all brown hyaena scats), suggests that they mainly scavenged. Jackal scats contained a higher proportion of small mammal remains, suggesting that jackals actively hunted more often than brown hyaenas did. The diets differed significantly between the two species, even though diet overlap was fairly high (0.79). Further analysis, albeit based on small sample sizes, suggests that diet of these mesopredators differ between protected reserves with apex predators and unprotected areas without apex predators, thus confounding generalizations. Further studies are therefore required to investigate possible mesopredator release when apex predators are absent.

Key words: apex predators, carnivore diets, scat analysis, brown hyaena, black-backed jackal.

$\mathrm{T}$

he extent of niche differentiation and resource 1 partitioning determines the degree to which different species can either coexist or competitively exclude each other (Pianka 1973; Carvalho \& Gomes 2004). An important mode of resource partitioning is the degree of dietary overlap between sympatric species (Hayward \& Kerley 2008). This overlap is influenced not only by each species' physical ability to obtain food (Radloff \& du Toit 2004; Owen-Smith \& Mills 2008), but

*Author for correspondence. Present address: Centre for Africa Conservation Ecology, Department of Zoology, Nelson Mandela Metropolitan University, Port Elizabeth, South Africa E-mail: cjtambling@gmail.com also by variation in the spatial and temporal availability of food (Azevedo et al. 2006). Complex and dynamic patterns of spatial and temporal coexistence within carnivore guilds therefore often require long-term studies to disentangle the interactions between predators and prey species (Carvalho \& Gomes 2004; Azevedo et al. 2006). However, where resources are limited, the strength of competition between sympatric species generally decreases with increased resource partitioning (Pacala \& Roughgarden 1985). These interspecific competitive interactions are mediated by inter-specific morphological, physiological and behavioural differences (Loveridge \& Macdonald 2003). Despite marked body size differences, brown hyaenas (Parahyaena brunnea; Hyaenidae) and black-backed jackals (Canis mesomelas; Canidae) (hereafter referred to as jackals) can be regarded as either mesocarnivores or apex predators, depending on the presence or absence of larger carnivores (see Ritchie \& Johnson 2009). As mesopredators, the potential food availability increases as dietary items previously unattainable (large herbivore species) are killed by apex predators, and interspecific competition can be expected to decline concomitantly. However, when acting as apex predators in the ecosystem, available food may be limited and differences in body size can lead to niche differentiation in terms of food size, and could also establish an inter-specific dominance hierarchy in which size reflects strength and superiority (Caro \& Stoner 2003). Resource partitioning based on body size is, however, complicated by group size, e.g. brown hyaenas may 
exclude single jackals (Mills \& Mills 1978; Lacruz \& Maude 2005), while groups of jackals may dominate brown hyaenas. The aim of this study was to explore the dietary overlap between these two carnivores at a regional level and introduce the idea of mesopredator release in structuring niche separation. Although numerous studies have investigated the diet of each species separately, few studies have investigated the overlap and resource partitioning, which may vary with the presence or absence of apex predators. To achieve this, we analysed scats collected from inside protected areas and privately owned farms in South Africa's North West Province $\left(26^{\circ} 21^{\prime}-27^{\circ} 50^{\prime} \mathrm{E}\right.$, $\left.24^{\circ} 13^{\prime}-25^{\circ} 50^{\prime} \mathrm{S}\right)$.

We assessed 1) the relative contribution of different broad prey groups to the diet of each species on a regional scale and 2) the dietary overlap of the two species. Sites from which samples were collected included formally protected areas; Atherstone Nature Reserve (ANR; 23500 ha), Pilanesberg National Park (PNP; 50000 ha) and privately owned game/cattle farms such as Mankwe Wildlife Reserve (MWR; 45000 ha). PNP is the only location with a fence designed to be predator-proof (van Dyk \& Slotow 2003). Seventyfive scats were collected ( 31 brown hyaena scats (protected areas, 21; private farms, 10) and 43 jackal scats (protected areas, 9; private farms, 34) along roads within the study sites during August 2006 and in January, February, April, May and June 2007. Trained observers identified samples to species level based on colour, dimensions, position and presence of additional animal signs. Appropriate spoor guides were consulted where necessary (Walker 1996; Stuart \& Stuart 2000). Samples were rated from one to five, with a rating of five indicating high confidence in the species identification. Only samples rated $>3$ were analysed. Dried scats were analysed using routine methods (Keogh 1983) and their contents macroscopically identified and separated into large mammals (adults $>10 \mathrm{~kg}$ ), small mammals (including rodents and shrews), birds, reptiles, invertebrates, fruit and anthropogenic items. We identified mammal species by comparing the physical appearance of hairs combined with cross-sections and cuticular scale patterns to available reference collections (Keogh 1979, 1983; Buys $\&$ Keogh 1984). We calculated dietary diversity $(H)$ from the scats of the two species using Brillouin indices and plotted the cumulative diversity $\left(H_{k}\right)$ against the number of scats collected to determine if the predator diets have been adequately sampled (see Glen \& Dickman 2006). We calculated percentage occurrence of each prey category in the total number of scats for each species as an indication of how often each species fed on each dietary component (Loveridge \& MacDonald 2003). The relative percentage occurrence (number of times a food item was encountered as a percentage of the total occurrence of all species) indicates the importance of each food item to the overall diet (Loveridge \& MacDonald 2003). The 95\% confidence intervals for both the percentage occurrence and the relative percent occurrence were generated from 1000 bootstrap simulations (Efron \& Tibshirani 1993; Andheria et al. 2007). We assessed relative differences between the two carnivores' diets using Fisher's exact tests, which are suited to handling small frequencies (Zar 1999). Pianka's index $(\alpha)$ (Pianka 1973) was used to calculate niche overlap between each pair of carnivores for the seven broad dietary categories where $\alpha=1$ indicates complete overlap and $\alpha=0$ indicates no overlap (see Loveridge \& MacDonald 2003). The use of a cumulative Brillouin index $\left(H_{\mathrm{k}}\right)$ indicated that on a regional scale, sample sizes were sufficient for jackal and brown hyaena when considering the broad prey categories investigated (Fig. 1). We found, on average, 1.96 and 1.77 dietary categories per jackal and brown hyaena scat, respectively. Large mammal remains were found in more than $50 \%$ of the scats for both species and were by far the most important dietary component for brown hyaenas (Table 1). We identified 16 species of large mammal (Artiodactyla and Perissodactyla), with impala (Aepyceros melampus) the most frequent, representing 39\% and 34\% occurrence of the diets of brown hyaena and jackal, respectively. Blue wildebeest (Connochaetes taurinus) contributed $19 \%$ to the diet of brown hyaena. No other large mammal made up more than $5 \%$ of the diet of jackal, with small mammals being more important (Table 1). The differences in large mammal and small mammal proportions between the diets resulted in a significant difference between jackal and brown hyaena diets across the region (Fisher's exact test: $P<0.05)$. However, at 79\%, the niche overlap between the species was still high. Jackal diet comprised high proportions of small and large mammals, corroborating previous reports that they both scavenge and hunt competently (Nowell \& Jackson 1996; Walton \& Joly 2003). Brown hyaenas, on the other hand, are predominantly scavengers (Owens \& Owens 


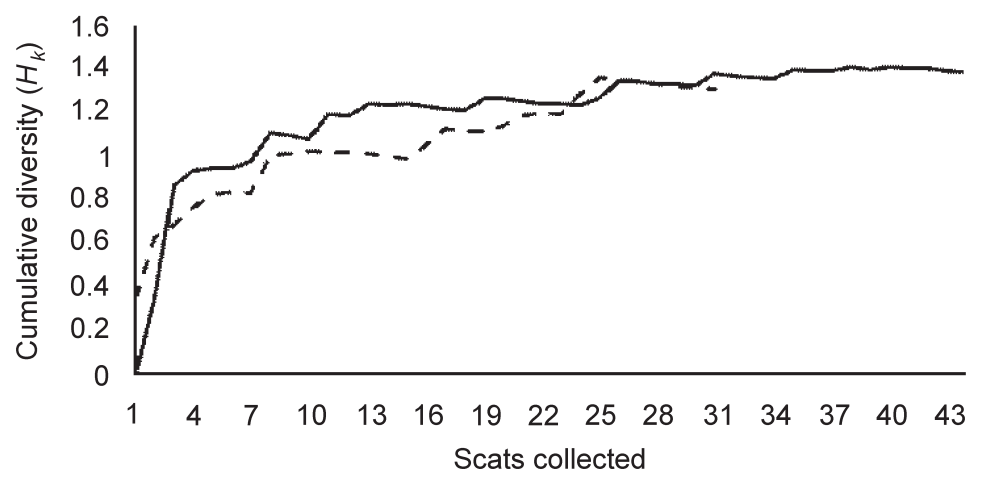

- Jackal - - - Brown hyaena

Fig. 1. Species accumulation curves based on the cumulative Brillouin index for jackal and brown hyaena scat samples in the North West Province, South Africa.

1978b). Thus, it is possible that jackals may have been excluded from carcass sites by the much larger brown hyaenas, forcing them to hunt more frequently (Owens \& Owens 1978a). This may be more likely to happen in PNP where brown hyaenas are abundant. Further investigation into the jackal diets, albeit with a low sample sizes, suggested that more large mammals are consumed outside of protected areas whereas more small mammals are consumed inside protected areas. This observation supports the idea that jackal may be excluded from scavenging sites and forced to actively hunt when competing with brown hyaena as mesopredators in protected areas. Giraffe (Giraffa camelopardalis) and buffalo (Syncerus caffer) remains in the brown hyaena scats were almost certainly scavenged from lion (Panthera leo) kills, as brown hyaena kills usually consist of small prey items such as lagomorphs (Owens \& Owens 1978b). Burgener \& Gusset (2003) found that the dominant remains in brown hyaena scats from a game ranch in the Waterberg region of Limpopo Province, South Africa, were also Artiodactyla, which they assumed were killed by other large carnivores in the area. The low frequency of smaller species in the diet of the brown hyaena may reflect sufficient carrion resources, as most samples originated in areas where the hyaenas were relegated to mesocarnivore status by the presence of apex predators. Both study species supplemented their diets with fruits, but not to the same extent as in arid areas where fruits play a significant role in water provisioning (Mills \& Mills 1978). Invertebrates were consumed by both species. The presence of invertebrates in brown hyaena diet may indicate scavenging, especially invertebrates associated with decomposition of carrion. In the unprotected areas, the relative dietary occurrence of invertebrates was lower, and the occurrence of plant matter higher, than in protected areas. If the consumption of invertebrates indeed reflects scavenging, then brown hyaenas may have had less access to carcasses in the absence of apex predators and thus have been forced to supplement their diet with vegetable matter. A niche overlap of $\sim 79 \%$ is

Table 1. Diet of jackal and brown hyaena, expressed as the percentage occurrence and relative percentage occurrence, with the $95 \% \mathrm{Cl}$ in brackets.

\begin{tabular}{lcccccc}
\hline & \multicolumn{2}{c}{ Percentage occurrence } & & \multicolumn{2}{c}{ Relative percentage occurrence } \\
\cline { 2 - 3 } & Brown hyaena & & Jackal & & Brown hyaena & Jackal \\
\hline Large mammals & $80.6(67.7-93.6)$ & $59.1(45.5-72.8)$ & & $45.8(34.4-56.9)$ & $30.5(22.9-38.5)$ \\
Small mammals & $22.6(9.7-38.7)$ & & $77.3(63.6-88.6)$ & & $12.9(5.4-21.4)$ & $39.6(33.3-46.7)$ \\
Birds & $3.2(0-9.7)$ & $9.1(2.3-18.2$ & & $1.8(0-5.6)$ & $4.5(1.2-8.5)$ \\
Invertebrates & $45.2(25.8-61.3)$ & $27.3(15.9-40.9)$ & & $25.3(16.4-33.9)$ & $13.7(8.3-19.2)$ \\
Seeds/fruits & $12.9(3.2-25.8)$ & $13.6(4.6-22.7)$ & & $7.2(1.8-13.3)$ & $7(2.4-12.2)$ \\
Anthropogenic & $3.2(0-9.7)$ & $4.6(0-11.4)$ & & $1.8(0-5.6)$ & $2.4(0-6.1)$ \\
Reptile & $9.7(0-22.6)$ & $4.60-11.36$ & & $5.2(0-10.9)$ & $2.2(0-5.1)$ \\
\hline
\end{tabular}


fairly high. Based on the limited sample sizes for the protected versus unprotected ecosystems, there was a greater degree of overlap in the unprotected areas than in the protected areas. This suggests that niche partitioning in protected areas in the presence of an apex predator results in a form of competitive exclusion of jackal at carcasses by brown hyaena, resulting in a greater level of hunting by the jackals. In the absence of an apex predator, the diets of the two species are more similar and brown hyaena may be forced to hunt more given reduced availability of scavengeable carcasses. Ultimately, across the region the diets of the two species are similar, but further work is needed in identifying how the presence or absence of apex predators influences the diets across a range of study sites. We now aim to expand on this work and explore the role of apex predators in formally protected and unprotected areas and their influence on the diets of small to mediumsized carnivores.

We would like to thank Earthwatch volunteers for help with the collection of the scats, as well as the North West Parks and Tourism Board, and all the private landowners who allowed us to collect scats on their properties. We thank Johnny Wilson and two reviewers for comments that helped improve the manuscript.

\section{REFERENCES}

ANDHERIA, A.P., KARANTH, K.U. \& KUMAR, N.S. 2007. Diet and prey profiles of three sympatric large carnivores in Bandipur Tiger Reserve, India. Journal of Zoology, London 273: 169-175.

AZEVEDO, F.C.C., LESTER, V., GORSUCH, W., LARIVIERE, S., WIRSING, A.J. \& MURRAY, D.L. 2006. Dietary breadth and overlap among five sympatric prairie carnivores. Journal of Zoology, London 269: 127-135.

BURGENER, N. \& GUSSET, M. 2003. The feeding habits of brown hyaenas (Hyaena brunnea) on a game ranch in Limpopo Province, South Africa. African Zoology 38: 181-184.

BUYS, D. \& KEOGH, H.J. 1984. Notes on the microstructure of hair of the Orycteropodidae, Elephantidae, Equidae, Suidae and Giraffidae. South African Journal of Wildlife Research 14: 111-119

CARO, T.M. \& STONER, C.J. 2003. The potential for interspecific competition among African carnivores. Biological Conservation 110: 67-75.

CARVALHO, J.C. \& GOMES, P. 2004. Feeding resource partitioning among four sympatric carnivores in the Peneda-Geres National Park, Portugal. Journal of Zoology, London 263: 275-283.

EFRON, B. \& TIBSHIRANI, R. 1993. An Introduction to the Bootstrap. Chapman \& Hall, San Francisco.

GLEN, A.S. \& DICKMAN, C.R. 2006. Diet of the spotted- tailed quoll (Dasyurus maculatus) in eastern Australia: effects of season, sex and size. Journal of Zoology, London 269: 241-248.

HAYWARD, M.W. \& KERLEY, G.I.H. 2008. Prey preferences and dietary overlap amongst Africa's large predators. South African Journal of Wildlife Research. 38: 93-108.

KEOGH, H.J. 1983. A photographic reference system of the microstructure of the hair of southern African bovids. South African Journal of Wildlife Research 13: 89-132.

LACRUZ, R. \& MAUDE, G. 2005. Bone accumulation at brown hyaena (Parahyaena brunnea) den sites in the Makgadikgadi Pans, northern Botswana: taphonomic, behavioural and palaeoecological implications. Journal of Taphonomy 3: 43-54.

LOVERIDGE, A.J. \& MACDONALD, D.W. 2003. Niche separation in sympatric jackals (Canis mesomelas and Canis adustus). Journal of Zoology, London 259: 143-153.

MILLS, M.G.L. \& MILLS, E.J. 1978. The diet of the brown hyaena (Hyaena brunnea) in the southern Kalahari. Koedoe 21: 125-149.

OWEN-SMITH, N. \& MILLS, M.G.L. 2008. Shifting prey selection generates contrasting herbivore dynamics within a large-mammmal predator-prey web. Ecology 89: 1120-1133.

OWENS, M.J. \& OWENS, D.D. 1978a. Feeding ecology and its influence on social organization in brown hyaena (Hyaena brunnea, Thunberg) of the central Kalahari Desert. East African Wildlife Journal 16: 113-135.

OWENS, M.J. \& OWENS, D.D. 1978b. Feeding ecology and its influence on social organization in brown hyenas (Hyanea brunnea, Thunberg) of the central Kalahari desert. East African Wildlife Journal 16: 113-135.

PACALA, S.W. \& ROUGHGARDEN, J. 1985. Population experiments with the Anolis lizards of St. Maarten and St. Eustatius. Ecology 66: 129-141.

PIANKA, E.R. 1973. The structure of lizard communities. Annual Review of Ecology and Systematics 4: 53-74.

RADLOFF, F.G.T. \& DU TOIT, J.T. 2004. Large predators and their prey in a southern African savanna: a predator's size determines its prey size range. Journal of Animal Ecology 73: 410-423.

RITCHIE, E.G. \& JOHNSON, C.N. 2009. Predator interactions, mesopredator release and biodiversity conservation. Ecology Letters 12: 982-998.

STUART, C. \& STUART, T. 2000. A Field Guide to the Tracks and Signs of Southern and East African Wildlife. Struik, Cape Town.

VAN DYK, G. \& SLOTOW, R. 2003. The effects of fences and lions on the ecology of African wild dog reintroduced to Pilanesberg National Park, South Africa. African Zoology 38: 79-94.

WALKER, C. 1996. Signs of the Wild: A Field Guide to the Spoor and Signs of the Mammals of Southern Africa. Struik, Cape Town.

WALTON, L.R. \& JOLY, D.O. 2003. Canis mesomelas. Mammalian Species 715: 1-9.

ZAR, J.H. 1999. Biostatistical Analysis. Prentice Hall, New Jersey.

Responsible Editor: G.N. Bronner 